\title{
The Breakthrough of Medical Physics Course in Independent Medical Colleges: Fragmentation Teaching and Micro Learning Resource
}

\author{
Benchao Zhu ${ }^{1,2, a^{*}}$, Weiwei Jiang ${ }^{3, b}$ and Fan Zhang ${ }^{3, c}$ \\ ${ }^{1}$ Institute of Medicine and Nursing, Hubei University of Medicine, Shiyan 442000, China \\ ${ }^{2}$ Hubei University of Medicine, Shiyan 442000, China \\ ${ }^{3}$ Hubei Dongfeng Automobile Technician College, Shiyan 442000, China \\ azbc@hbmu.edu.cn, bjww0507@163.com, ${ }^{\mathrm{c}} 326386321 @ q q . c o m$
}

\begin{abstract}
Keywords: Medical physics course; Independent medical colleges; Fragmentation Teaching; Micro Learning Resource
\end{abstract}

\begin{abstract}
After showing the proper function of the medical physics course, the independent medical colleges' students' learning ability, employment and colleges' funding and other practical problems, the paper analyzes why the medical physics course is in trouble. Then, this paper focuses how to break through this awkward dilemma, two important teaching methods, Fragmentation Teaching and Micro Learning Resource, are introduced to medical physics teaching. Finally, from the basic principles of higher education and the reality of the independent medical colleges, the logic diagram of how fragmentation teaching and Micro Learning Resource help medical physics course breaking through the difficulty in independent medical colleges, is also presented.
\end{abstract}

\section{Introduction}

Restricted by funds, college entrance examination policy, people's concept of education and other factors, independent medical colleges are always marked as the application oriented type colleges [1]. Although this type of application is undergraduate level, not the junior level of higher Vocational College, the independent Medical Colleges are guided by the usefulness of the courses, so as to do their best to delete some public basic courses [2]. In the understanding of independent medical colleges' administrators, the most common useless courses are medical mathematics and medical physics, and even basic chemistry [3]. In a number of independent medical colleges, combined with funding factors, there are no medical mathematics, medical physics and basic chemistry in the training program for clinical medical students. This is obviously an abnormal phenomenon, and contrary to the basic principles of Higher Education. However, if one required independent medical colleges students learning all kinds of courses as the same as the first-class medical university students, it is only in the form of respect for higher education, in essence, contrary to the basic reality. In consideration of the independent medical colleges' students' learning ability and foundation, graduate employment scope, colleges' characteristics and other factors, many basic courses must be changed to adapt to the students of independent medical colleges. How to adjust the teaching content and teaching method has always been a hot topic in the research of independent medical college educators [4].

The structure of this paper is as follows, totally, this paper will focus on one of the basic public courses, medical physics. Then, by presenting the current situation of medical physics teaching in independent medical colleges. In order to break through the dilemma of medical physics teaching, at the end of the paper, two important teaching methods, Fragmentation Teaching and Micro Learning Resource, are introduced to medical physics teaching. Finally, we present why that those two teaching methods can help medical physics course breaking through the current teaching dilemma.

The current situation of medical physics course teaching independent medical colleges. Medical physics is the application of the principles and methods of physics to the prevention, diagnosis, treatment and health care of human diseases [5]. The function of medical physics course [5] can be seen in the following figure 1 . 


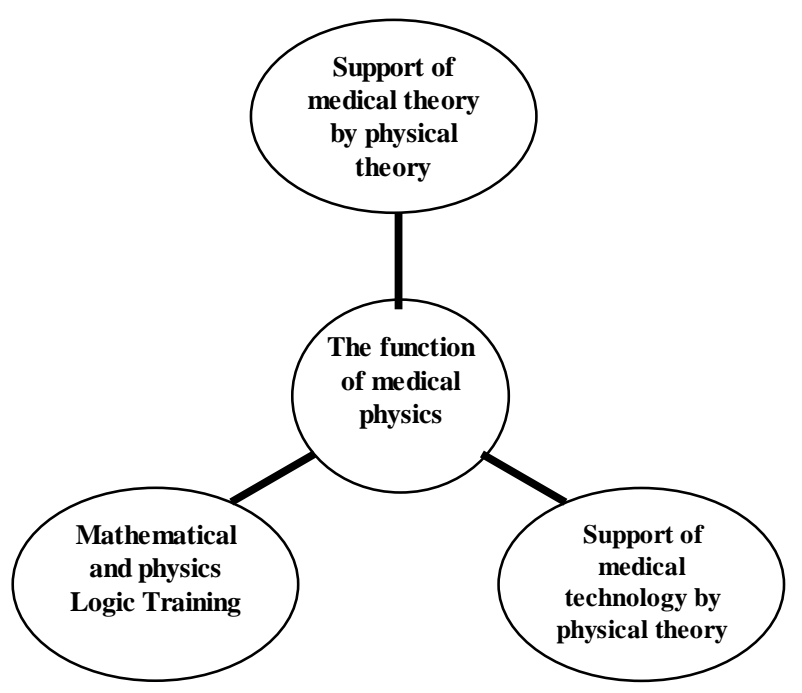

Figure 1 Functions of medical physics course

Accordingly, the relationship among medical colleges' position, training plan and students' employment can be seen in Figure 2
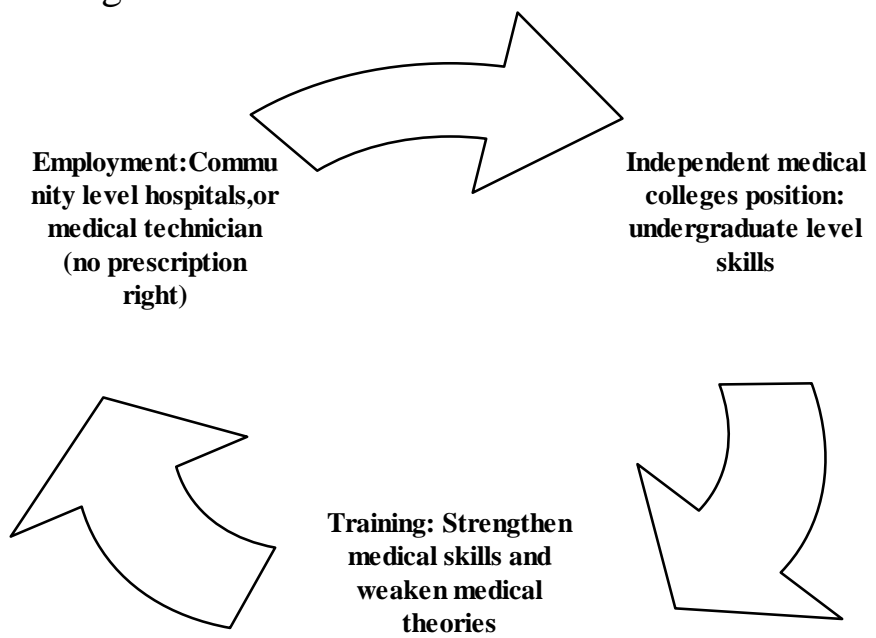

Figure 2 The cycle of colleges' position, students' training plan and employment

As the Fig.1 and Fig. 2 show above, two kinds of functions, support of medical theory and mathematical logic training, run counter to Fig. 2. This leads to Independent medical colleges usually hold a negative attitude toward medical physics. Finally, the actual situation is that independent medical colleges do not require all medical students to study physics. For example, the institute of Medicine and Nursing, Hubei University of Medicine, where the author is teaching now, the specific practices are as follows: on the one hand, in order to save the costs, the college directly delete the physics course of medical clinical specialty. On the other hand, in order to strengthen the comprehensive skills of students, for medical imaging specialty, medical rehabilitation specialty, and so on, the college requires students to learn certain physical courses again. So, we can safely conclude that the medical physics course is in an awkward position in independent medical colleges.

The fragment teaching and micro learning resource. How to change the awkward situation of medical physics course, which is given in the last section, is a thorny issue in the field of Higher Education [6]. We can solve the difficulties of medical physics teaching not only by the basic principles of education, but also respecting the actual needs of independent medical colleges' students. This section 
focuses on the principles of Pedagogy. Here, we introduce two advanced teaching concepts and forms: fragment teaching and micro teaching. The reasons why medical physics course is unpopular in independent medical colleges, are because of the rigorous theoretical structure and logical derivation. If we insist on the integrity of the theoretical framework and the logical training of Physics as the Fig. 1 shows, no matter how advanced teaching method is adopted, and no matter how famous physics teachers can not break through the difficulty of physics teaching in independent medical colleges. Fortunately, if give up the traditional physics education, fragment teaching and micro learning resource can help us breaking through the awkward situation of medical physics course in independent medical colleges.

Fragmentation is also known as fragmented learning [7]. Fragmented learning is to learn the content or learning time for segmentation, so that students learn the contents of the fragmentation of learning, such a learning approach is known as fragmented learning. It can be introduced to students in a formal or informal manner. Fragmentation learning is characterized by higher flexibility, more targeted, higher absorption rate. It is necessary to clarify that Fragmentation learning has a long history, and the fragmentation of knowledge itself is not an advantage, but the advantage of the effective is by using fragmented after giving users value, this value is derived from the fragmentation of the user's needs, and the fragmentation of demand is changing with the change of situation.

Micro learning resource can ultimately enhance the function of fragmentation teaching, because micro learning resource is the use of information technology in accordance with the laws of cognition, the fragmentation of learning content, process and the extension of the structure of the digital material resources. The main features of the micro learning resource [8] can be seen from the following figure 3

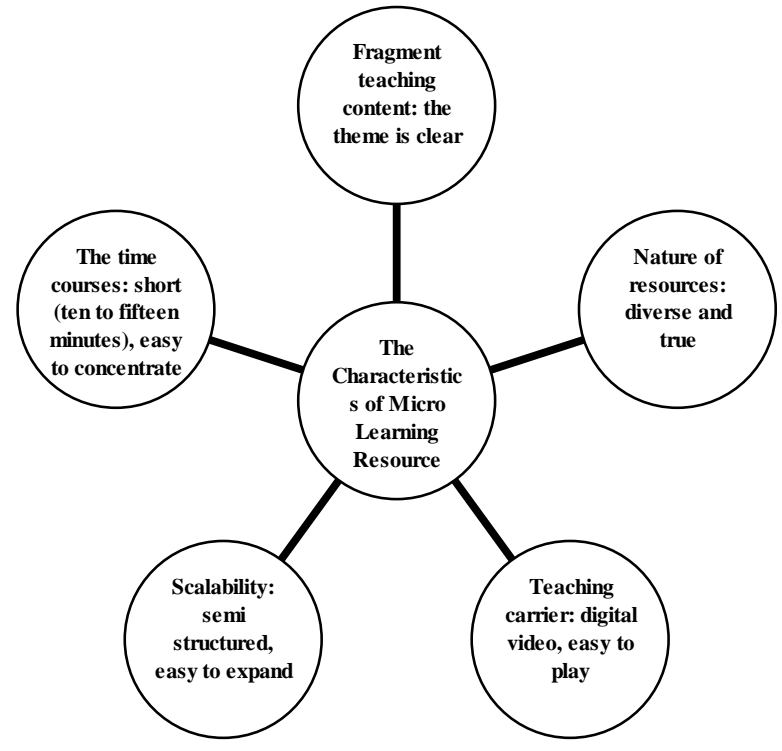

Figure 3 The Characteristics of Micro Learning Resource

As the Fig. 3 shows above, the useful fragment medical physics contents can be embedded into a short video by micro learning resource, this can fundamentally solve the contradictions raised in the previous section. We will discuss the specific solutions in the next section.

The breakthrough of medical physics course teaching in independent Medical Colleges by fragmentation teaching and Micro Learning Resource. The necessity of medical physics course, and how the micro learning resource help medical physics teaching meeting the independent medical college students' training and employment can be seen in the following logic diagram figure: 


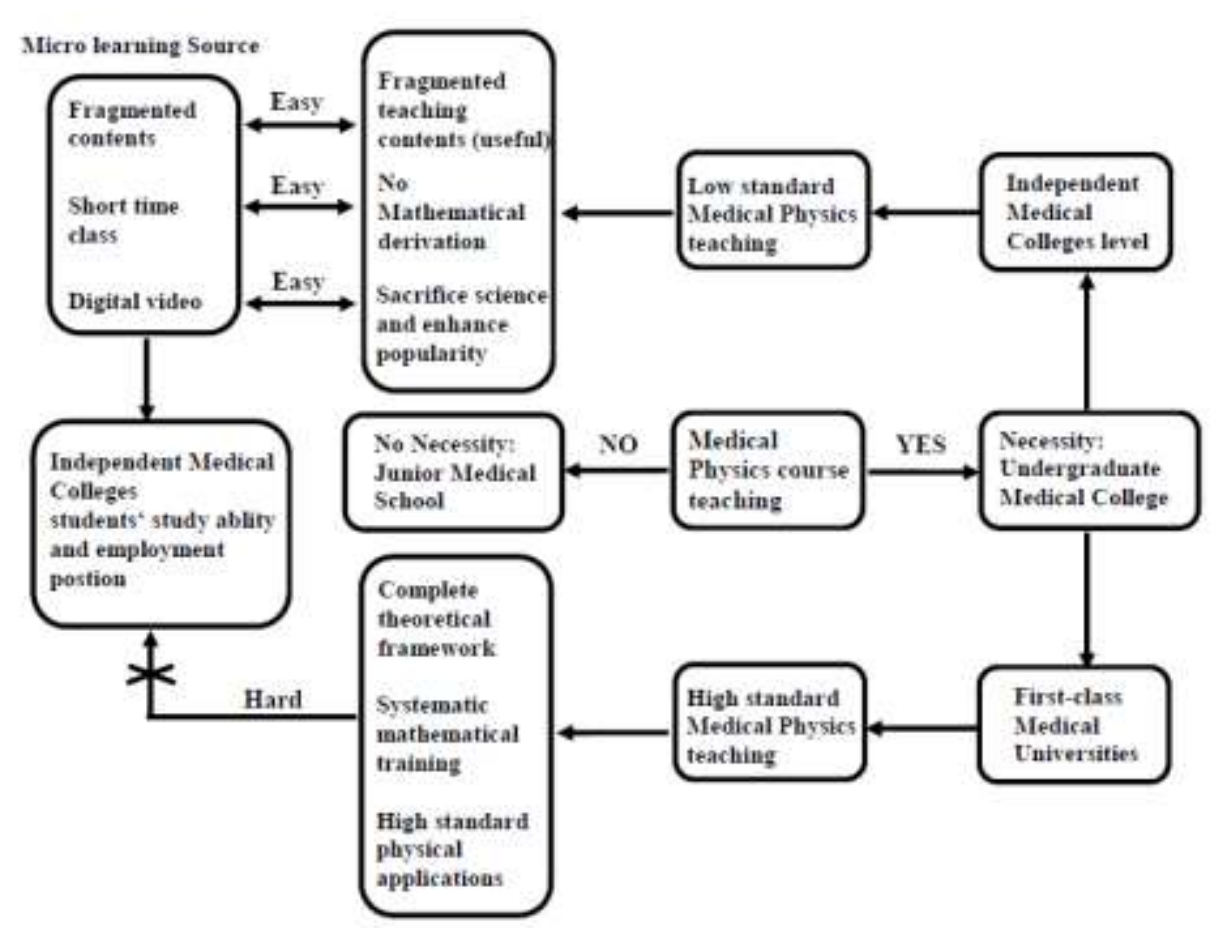

Fig 4 Logic diagram of the function of Medical Physics Micro Learning source

As the Fig. 4 shows that, the teaching mode of medical physics of first-class Medical Universities is not suitable for independent medical colleges' students' ability and employment. On the other hand, in the Micro Learning Resource, the fragmentation of teaching content and the small capacity of the classroom, as well as the interactive mode of digital video network, completely adapt to independent medical colleges' students' learning ability and employment direction. In independent medical colleges, if we do not carry out the fragmentation of teaching content, and also do not respect the reality while adhering to the principles of traditional education, medical physics teaching will be very difficult. This can explain why so many independent medical colleges choose directly deleting Medical Physics course. Once adopted Micro Learning Resource, there is no necessity to completely abandon the entire medical physics course, but to give up the rigor and integrity of medical physics courses, we can choose the content of "useful" in medical physics to serve for the cultivation of medical students [9]. For example, first choosing the application of the viscous fluid Poiseuille formula of fluid mechanics in hypertensive disease, the application of additional pressure of curved surface in alveolar respiration, geometrical optics imaging applications of the eyes, and so on. Then, recorded into a short, interesting video teaching file, in the form of interactive classroom teaching through the Internet.

\section{Summary}

In this paper, we firstly introduce the current situation of medical physics course teaching independent medical colleges. Then analyzing how to change the awkward situation of medical physics course, two important teaching methods, Fragmentation Teaching and Micro Learning Resource, are introduced. Finally, the logic diagram of how fragmentation teaching and Micro Learning Resource help medical physics course breaking through the difficulty in independent medical colleges is also presented.

\section{Acknowledgements}

This work is supported by the Institute of Medicine and Nursing, Hubei University of Medicine, 2016 teaching research project fund, N0. YHJ2016014. 


\section{References}

[1] Zheng-Qiang Wang, Wan-Guo He, Zong-Mo Cai, The development of Independent Colleges in China: present situation, difficulties and solutions, Higher Agricultural Education. 2017, (1) 15-18.

[2] Kun-Ming Que, Analysis on the current situation and Countermeasures of Independent Colleges in China, Educational Research, 2016 (3) 64-71.

[3] Fang $\mathrm{Wu}$, Discussion on the current situation of personnel training and the improvement of training quality in Independent Colleges, Journal of Huanghe S\&T University, 2016, 18 (5) 6-10.

[4] An-Ming Liu, Xin-Jia Li, Investigation on the study situation of independent college, Forum on Contemporary Education, 2016 (2) 1-8.

[5]Lei Wang, Min Ji, Medical Physics ( $8^{\text {th }}$ Edition), People's Medical Publishing House, Bei Jing, 2013, pp. 1-4.

[6] Wei Jian, Research on the necessity of teaching reform in Independent Colleges, Journal of knowledge economy, 2017 (1) 169-169

[7] Wang Yu, Zhou Yuqing, research on the "ten minute theory" in MOOC and the fragmentation Teaching, Journal of time education, 2016 (17) 189-189

[8] PJ Guo , J Kim , R Rubin, How video production affects student engagement: an empirical study of MOOC videos, Acm Conference on Learning, 2014, 43 (2) 41-50.

[9] Ye Liying, Yang Qiong, Liu Limei, Research on the feasibility of "MOOC" in the teaching of Medical Physics, Biotech world, 2016 (5) 299-299. 